\title{
Impact of online course discussion on education leadership students' reflections
}

\author{
Amany Saleh \\ Center for Excellence in Education, Arkansas State University, USA
}

\begin{tabular}{l} 
Article Info \\
\hline Article history: \\
Received Nov 13, 2019 \\
Revised Apr 4, 2020 \\
Accepted Apr 25, 2020 \\
\hline Keywords: \\
Educational leadership \\
Online discussions \\
Reflective practices
\end{tabular}

Corresponding Author:

Amany Saleh

Center for Excellence in Education

Arkansas State University

State University, AR 72467, USA.

Email: asaleh@astate.edu

\begin{abstract}
Educators learn through reflecting on how power shapes their own practices, expressing their concerns about the constraints they face, and brainstorming solutions to address them. Educators create and adjust their philosophies and practices through reflection on how abstract theories manifest themselves in life. The online discussion format affords students the opportunity to improve their reflective practices through the use of structured questions, supervised scaffolding, shared experience, and opportunities to connect theory to practice. In essence, online discussions offer educators a dynamic and energetic atmosphere in which they can interact with each other. The purpose of the study was to examine the impact of online discussions on students' critical skills as they reflect on issues dealing with students' diversity. The results demonstrated that the use of structured online discussions contributed to the elevation of graduate students' reflective practices as they contemplated the social and cultural issues that impact students' learning and their educational practices.
\end{abstract}

This is an open access article under the CC BY-SA license.

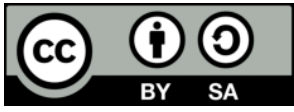

\section{INTRODUCTION}

Building on the works of Karl Marx, Michael Foucault, Edward Said, and Paulo Freire, the author uses the critical theory approach to empower learners to critically analyze and evaluate the complex impact students' diversity has on education. The author employs critical readings and discussion questions focused on learning environment diversity and social justice as tools to help students examine the social and cultural issues that impact their educational practices. Hollway and Gouthro argued that educators, even those who work in primarily white schools, should be cognizant that their students will graduate to work in diverse societies. Challenging educators to think of global issues beyond their personal and local experiences help them address diversity issues more positively [1].

Jones and Ryan asserted that pre-service teachers are usually left alone to make the connection between theory and practices in the classroom. They argued that structured online discussion promotes reflective thinking practices [2]. Health care education students reported in a study that online discussions promote reflection and allow time for social interaction [3].

In a quasi-experimental study comparing undergraduate students' reflections in a weekly online discussion to a hard-copy journal submitted to the instructor, the researchers found that students who participated in the online discussion enjoyed the process and were more satisfied with their achievement as 
compared to those who did not [4]. Other studies conducted by Wise and his colleges and Wu found that online communication promoted reflectivity and engagement among groups of undergraduate students [5-7].

\section{RESEARCH METHOD}

The author examined the effects of purposeful readings and reflections on increasing awareness of graduate educational leadership students of issues related to equity in education. A social justice theme was chosen for the doctoral course. Changes in students' comments on issues such as poverty, gender inequality, cultural beliefs, and educational policies as well as their impact on students' learning, were recorded.

The participants in this study were seventeen doctoral students enrolled in educational leadership classes at a university in southern United States. A majority of the participants were current school leaders. The students were enrolled in a hybrid class that required students to attend Zoom (a tele-conference forum that affords the teacher and students to meet synchronously via their computers that have cameras) class meetings and participate in a weekly online class discussion forum. The students' comments in the online discussion forum were collected.

Students were asked to read assigned course texts and examine how social, political, cultural, and economic factors impact students' learning and school practices. The students were required to read assigned chapters ahead of class and come prepared with responses to weekly structured questions. The questions/prompts were posted on the course website ahead of class meetings. After Zoom class meetings, the students were tasked to reflect on the readings and engage in an online class discussion as they relate to their educational practices for a whole week.

A content analysis method of students' comments was used to determine if the students changed the level of their reflections as a result of their participation in the online discussion. Based on the earlier work of Van Manen [8], Hatton \& Smith [9] and Lee [10] on reflection level classification, the author used a threelevel hierarchy to classify students' reflections:

a. Descriptive; in which the writer only gives a descriptive recount of a discussion, presentation or a text,

b. Analytical; in which the writer analyzes the text, discussion, or presentation in light of a personal experience or a perspective,

c. Critical; in which the writer considers the social, political, and historical factors that may have impacted the situation covered in the reading or discussion.

The author highlighted texts from students' comments indicating different levels of reflections weekly. Each paragraph was assigned a reflection level based on the above classification. Individual graphs were drawn to determine if students' comments demonstrated a change in their level of reflection after they participated in course activities, illustrated in Figure 1.

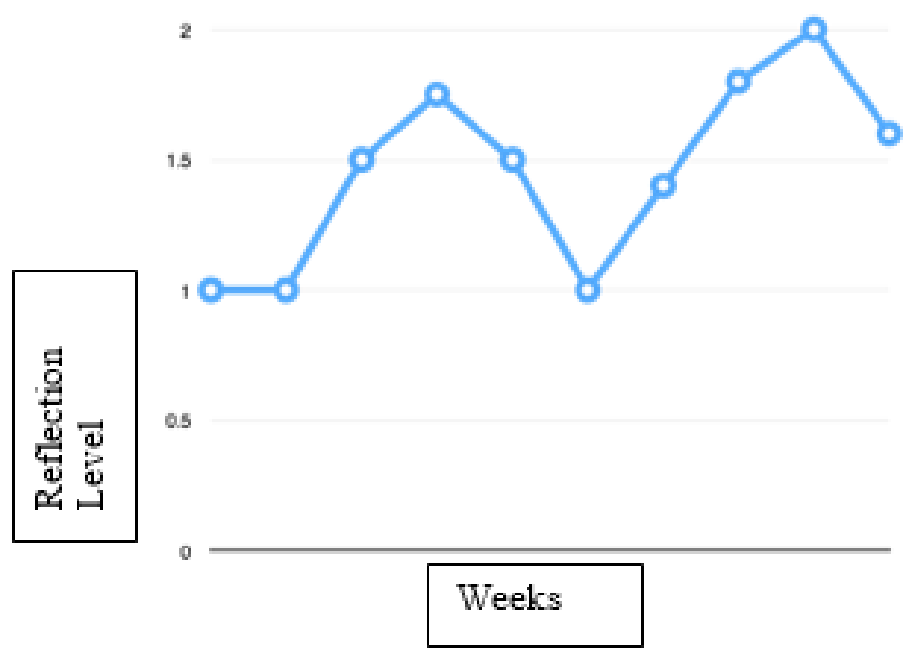

Figure 1. Example of individual students' progress of reflections

\section{RESULTS AND ANALYSIS}

Impact of online course discussion on education leadership students' reflections (Amany Saleh) 
Results demonstrated a majority of students started at the beginning of the course mainly focusing on describing/summarizing the issues discussed in the readings and class. Through structured questions and class discussion, students were encouraged to take an in-depth look at concerns expressed in the readings. Students were prompted to examine how social issues may impact their own practices even though it may appear, at first, unrelated or inapplicable to their own context.

The results of this study clearly demonstrated that the delivery mode of the class, specifically, the use of the online discussion, has contributed to enhancing the level of students' reflections as evidenced in their comments and in responses to the teacher questions. This could be due to the time the students had to reflect on each other's comments, provide research support for their ideas, and share web links with the group. The teacher also had time to post more questions, provide clarification, and steer the students back to the focus of the discussion when they tended to get off track.

The following paragraph is an example of a student's reflection at the descriptive level. In this comment, the student is typically describing the process offered by the author without attaching to it a personal value or reflecting on what it means to students' learning or how it affects her own practices.

With a banking system, there is an order to the process. As educators reflect on immovability in the process of leaning. Educators disseminate their knowledge and students absorb that knowledge and then utilize that knowledge to respond to assessments, create solutions to problems but there is never a question to the status quo.

On the other hand, this following comment is an example of a student's reflection at the analytical level. In this paragraph, the student reflects on what Friere's ideas mean and how the ideas relate to her own experience. She also links the ideas presented by the author to other literature she read and finally she discusses what these concepts mean to her.

\begin{abstract}
My interpretation of Freire's statement, "without this faith in people, dialogue is a farce which inevitably degenerate into paternalistic manipulation" (p. 91), is formulated through my personal experiences as well as how my beliefs as an educator have evolved in my own learning process. Leading up to this statement, Freire describes prerequisites to the dialogue as humility, hope, faith; yet, not naïve. Focusing on one particular aspect, faith, which I understand as complete confidence and trust, I am wondering how likely those who have experienced some type of oppression will trust even those in a similar situation. After an examination of the literature across the social science field, Teschannen-Moran (2014), defined trust, “Trust as an individual's or a group's willingness to be vulnerable to another party based on the confidence that the latter party is benevolent, reliable, competent honest, and open" (p. 20-21). She describes trust as a convoluted dynamic concept that is ever evolving. I believe without the ability and willingness to arrive at this state of vulnerability, dialogue among those within the struggle will be dominated by the unwilling participant, therefore, supporting the divided role of the oppressor and the oppressed.
\end{abstract}

The following paragraph is one example of a reflection at the critical level. In this paragraph, the student not only considers the impact of the ideas presented by Friere on her personal experience, but also discusses what she will do in the future to positively impact students' learning and improve her educational practices. She reflects on the long-term impact of social and cultural issues, discussed in the class and the readings, on students learning which elevates her reflection to the critical level.

I think Freire is very insightful and his views have caused me to really deliberate on my own education, the way I want to learn, and the way I hope to one day "teach." It has also caused me to reflect on the current state of our union, and be glad that we are not as oppressive as some educational cultures in the world, but determined to uncover the oppression in our system by increasing the dialogue with others. Friere says, "the earlier dialogue begins, the more revolutionary the movement will be. "I see a real need right now to become more revolutionary and help others to see the oppression who "reduce men to the status of "things" which is where I believe our political discourse to have devolved.

The online discussion offers an opportunity for educators to enhance their teaching methods and provide students with a forum in which they can express their views and receive feedback. The students get exposed to different points of view, which help them expand their thinking and, in many cases, alter their previously held beliefs. This is achieved largely by the fact students have the time to reflect, respond, argue 
and, sometimes, conduct their research just to provide support for their views. Thus, online class discussion affords students the chance to reflect on each other's comments and respond to them in a comprehensive fashion. These findings were supported in an earlier study conducted by Bye et al, [4].

The results indicated that a significant number of students reflected at the first level at the beginning of the course, but a large percentage of them progressed to a higher classification by the end of the course. However, at the beginning, few students expressed frustration with the readings failing to see the connection between the context and their daily practices. This frustration was reported in Holloway and Gouthro's research of undergraduate and graduate reflective writing [1]. They attributed this resistance to the rarity of students' exposure to critical theory and the use of serious analysis of sensitive issues such as discrimination, racism, etc. This rationale was supported in the current study. Students commented they were never exposed to critical readings and they were rarely asked to examine the long-term impact of their own practices.

The online format helps teachers and students create a true learning community where they can relate to each other and build strong rapport among each other at a more meaningful level. In this learning community, all participants' views are valid and respected. In this environment, teachers and learners are truly co-learners who are encouraged to consider each other's views and think beyond their familiar boundaries. This factor could be the contributing element to increasing students' reflective levels.

\section{LIMITATION}

This study had a number of limitations. It is important to note that the study relied on the author's interpretations of students' comments to classify them into different reflective levels which serves as a limitation for this study. An additional limitation is that the design of the study did not allow for making strong inferences about the causes of the changes in reflection levels because of the numerous variables that may have had an impact on the results $[2,11]$. Another limitation was that students' comments relied heavily on the instructor's engineered questions of the discussion that elicited reactions from the students, which may have had an impact on students' responses. The availability of time (a full week for each discussion topic) allowed the teacher to post comments and questions for students every time they tended to stray from the issue to discuss, which helped keep them focused on the issues in the online discussion. A feature that is not possible in traditional face-to face classes. One last limitation was the small size of the sample which limits the generalizability of the study results [2].

\section{CONCLUSION}

The literature suggests that online discussion which requires reflecting on others' thoughts and involves the risk of being challenged or challenging others' point of view, actively engages students in the learning process as found in the writing of Jones and Ryan [2] and Cooner [12]. Fostering and improving reflective practices can be achieved through the use of structured questions [9, 14, 13], supervised scaffolding $[13,14]$, shared experiences [15], and opportunities to connect theory to practice [16]. The results of this study affirmed the earlier findings.

In this study, the online discussion forum proved itself to be a successful tool for this educator in order to provide a think tank that allows participants to contribute, making it one of the richest learning communities in our present day. The online discussion forum encourages teachers and students to reflect back on their practices, question their previously held beliefs and brainstorm ideas on how to better themselves as learners and teachers. In this study, the discussion enhanced educators' understanding of factors impacting their practices, raised their awareness regarding their own biases and beliefs, increased their sensitivity to students' needs, and established links between theory and practice [17]. The author argues that the synergy generated by online dialogue has the largest impact on the quality of teaching and learning. The online format allows students time and flexibility to reflect on ideas expressed in the discussion. The online setting afforded the students the time and freedom to express their thoughts, read their classmates' responses, and reflect on the impact of their beliefs on their daily practices in schools. The once-a-week, face-to-face meetings did not allow students the time and settings to reflect on their ideas to the same degree. Therefore, when it comes to promoting reflective practices, the online discussion proved to be a superior tool for educators to employ.

\section{REFERENCES}

[1] S. A Holloway and P. A Gouthro, "Teaching resistant novice educators to be critically reflective," Discourse: Studies in the cultural politics of Education, vol. 32, no. 1, pp. 29-41, 2011.

[2] M. Jones and J. Ryan, "Learning in the practicum: Engaging pre-service teachers in reflective practice in the online space," Asia-Pacific Journal of Teacher Education, vol. 42, no. 2, pp. 132-146, 2014. 
[3] R. Nilsen and L. Lundvoll Nilsen, "Interprofessional participation and reflection in a digital network," Seminar.net, vol. 9, no. 1, 2013, [Online] Available: http://seminar.net/volume-9-issue-1-2013/205-interprofessionalparticipation-andreflection-in-a-digital-network.

[4] L. Bye, S. Smith, and H. Monghan Rallis, "Reflections Using an Online Discussion Forum: Impact on Students Learning and Satisfaction," Social Work Education, vol. 28, no. 8, pp. 8410855, 2009.

[5] A. Wise, N. Perera, Y-T, Hsiao, J. Speer, and F. Marbouti, "Microanalytic case studies of individual participation patterns in an asynchronous online discussion in an undergraduate blended course," The Internet and Higher Education, vol. 15, no. 4, pp. 108-117, 2012.

[6] A. Wise, J, Speer, F. Maraboutic, and Y-T Hsiao, "Broadening the notion of participation in online discussions: Examining patterns in learners' online listening behaviors," Instructional Science, vol. 41, no. 2, pp. 323-343, 2013.

[7] D. Wu and R. Hiltz, "Predicting learning from asynchronous online discussions," Journal of Asynchronous Learning Networks, vol. 8, no. 2, pp. 139-152, 2004.

[8] M. Van Manen, "Linking ways of knowing with ways of being practical," Curriculum Inquiry, vol. 6, no. 3, pp. 205-228, 1997.

[9] N. Hatton and D. Smith, "Reflection in Teacher Education: Towards Definition and Implementation," Teaching and Teacher Education, vol. 11, no. 1, pp. 33-49, 1995.

[10] H. Lee, "Understanding and Assessing Pre-service Teachers' Reflective Thinking," Teaching and Teacher Education, vol. 21, no. 6, pp. 699-715, 2005.

[11] A-B, Enoch son, "Reflective discussions in teacher training: A comparison between online and offline discussions of course literature in a class of pre-service teachers," Educ Inf Technol, vol 23, pp. 303-319, 2018.

[12] T. Cooner, "Dialectical constructivism: reflections on creating a web-mediated enquiry-based learning environment," Social Work Education, vol. 24, no. 4, pp. 375-390, 2005.

[13] A. Saleh, "Promoting social justice through reflective journaling," International Journal of Global Education, vol. 4, no. 3, pp.11-20. 2015..

[14] E. G. Pultorak, "Following the Developmental Process of Reflection in Novice Teachers: Three Years of Investigation," Journal of Teacher Education, vol. 47, no. 4, pp. 283-291, 1996.

[15] C. Zeki, "The Importance of Guiding Questions in Reflective Journaling," Hacettepe University Journal of Higher Education, vol. 2, pp. 282-292, 2012.

[16] M. Gallego, "Professional development of graduate teaching assistants in faculty-like positions: Fostering reflective practices through reflective teaching journals," Journal of the Scholarship of Teaching and Learning, vol. 14, no. 2, pp. 96-110, 2014.

[17] Z. Genc, "Teacher Autonomy through Reflective Journals Among Teachers of English as a Foreign Language in Turkey," Teacher Development, vol. 14, no. 3, pp. 397-409. 2010. 